\title{
Síntese e caracterização de nanopartículas de ouro por técnicas de microscopia e tomografia eletrônica
}

\author{
Oliveira JP ${ }^{1}$, Barbosa LS ${ }^{1}$, Prado AR ${ }^{2}$, Pontes MJ ${ }^{2}$, Ribeiro MRN ${ }^{2}$, Nogueira BV ${ }^{1}$, \\ Guimarães MCC ${ }^{1}$ \\ Laboratório de Ultraestrutura Celular Carlos Alberto Redins, Dep.Morfologia, CCS / UFES, Vitória - ES, Brasil \\ ${ }^{2}$ Laboratório de Telecomunicações, Dep. Engenharia Elétrica, CT / UFES, Vitória - ES, Brasil
}

\begin{abstract}
Resumo
Aqui nós relatamos a demonstração experimental de um método de tomografia eletrônica que atinge resolução em escala nanométrica, bem como a caracterização microscópica das nanoparticulas de ouro sintetizadas por redução química (Citrato de Sódio e Borohidreto de Sódio) com o auxílio da microscopia eletrônica de transmissão e varredura, microscopia de força atômica e o espectro UV-visível. Pela microscopia eletrônica de transmissão e pelo espectro UV-visível foi possível determinar o diâmetro das nanoparticulas de ouro sintetizadas. A morfologia da superfície e estrutura 3D das nanoestruturas apresentaram formas predominantemente esféricas e as imagens de microscopia eletrônica e varredura e de força atômica mostraram a dispersão e estabilização do material sintetizado.
\end{abstract}

Palavras chaves: nanopartículas de ouro, tomografia eletrônica, microscopia eletrônica.

\section{Introdução}

As particularidades das nanopartículas de ouro (AuNPs) têm estimulado áreas distintas de pesquisas nos últimos anos. A exploração das propriedades ópticas, eletrônicas e magnéticas destes materiais tem permitido seu emprego em diferentes campos de aplicação, tais como na construção de biossensores, em sistema de liberação gradativa de drogas, lubrificantes, células solares, catálise e outros [1].

Rotineiramente, os coloides de ouro são preparados por redução química de um precursor de ouro adequado, normalmente $\mathrm{HAuCl}_{4}$, e um agente redutor que pode ser um ácido orgânico, açúcar, aldeído, álcool e outros agentes redutores fortes. A forma e o tamanho de AuNPs dependem de diversas variáveis de processo, tais como concentrações dos reagentes, temperatura, $\mathrm{pH}$, surfactantes, aditivos, etc. Vários autores já discutiram os efeitos dessas variáveis de processo sobre a cinética de formação, tamanho e morfologia de AuNPs [2]. A redução química por citrato é um método bem conhecido para preparar nanopartículas de ouro monodispersas esféricas e método de síntese por borohidreto também se destaca pelo considerável rendimento gerado no processo de produção [3].

A microscopia eletrônica de transmissão é uma ferramenta de imagem poderosa que encontrou ampla aplicação em ciência de materiais, nanociência e biologia. Para revelar a estrutura tridimensional (3D) de amostras microscópicas, a tomografia de elétrons é o método de escolha com resolução em nanômetros cúbicos atualmente possível. O objetivo deste trabalho foi sintetizar e caracterizar nanopartículas de ouro por microscopia eletrônica e tomografia de elétrons.

\section{Materiais e Métodos}

Para a síntese dos nanomateriais metálicos, duas rotas de síntese química foram realizadas de acordo com otimização previamente determinada por este grupo de pesquisa. Sendo utilizado uma solução precursora de ouro, o ácido cloroáurico (HAuCl4 2,5 x 10-4) com os agentes redutores, Citrato de Sódio $\left(\mathrm{Na}_{3} \mathrm{C}_{6} \mathrm{H}_{5} \mathrm{O}_{7}\right.$, Merck) de concentração $1 \% \mathrm{p} / \mathrm{v}$ e tempo de síntese $15 \mathrm{~min}$, e o borohidreto de Sódio $\left(\mathrm{NaBH}_{4}\right.$, Merck) de concentração $3 \% \mathrm{p} / \mathrm{v}$ e tempo de síntese $5 \mathrm{~min}$. A síntese ocorreu em temperatura ambiente e sob agitação de 80 rpm. Após a etapa de síntese, amostras de nanopartículas de ouro (AuNP's) foram recolhidas e as suas propriedades ópticas foram avaliadas por espectrofotometria no UV - vis (Evolution 300, Thermo). O tamanho e a morfologia das nanopartículas de ouro foram examinadas por Microscópio Eletrônico de Transmissão (TEM 1400-JEOL), Microscópio Eletrônico de Varredura (SEM, 1610LV - JEOL) e Microscópio de Força Atômica (Shimadzu, SPM-9600). A tomografia eletrônica foi realizada no microscópio eletrônico de transmissão com auxílio do software SerialEM. Após a aquisição das imagens o software livre IMOD foi utilizado para a geração dos modelos tridimensionais das nanopartículas. 


\section{Resultados e Discussão}

A resposta óptica das nanopartículas metálicas sintetizadas com o citrato e o borohidreto de sódio apresentou picos bem definidos por volta dos 530 - 550 $\mathrm{nm}$, demonstrando diferentes absorbâncias para os dois agentes redutores utilizados, conforme pode ser observado na figura 1. Uma importante consideração a ser feita é com relação aos comprimentos de onda obtidos no pico de absorção do borohidreto de sódio que é inferior ao obtido com citrato de sódio. Tais fatos demonstram claramente a diferença nos mecanismos de formação das AuNPs nos dois sistemas. Os íons citrato além de participarem do processo de redução do ouro ajudam a promover a estabilização das nanopartículas formadas, fato que possibilita a formação de partículas com volume superior aos obtidos com borohidreto. Por outro lado, o borohidreto apresenta uma maior eficiência no processo de redução do ouro, gerando assim uma maior quantidade de núcleos formadores das AuNPs. Como resultado a dispersão obtida com borohidreto apresenta uma maior concentração, ou seja, maior absorbância e um menor comprimento de onda de absorção.

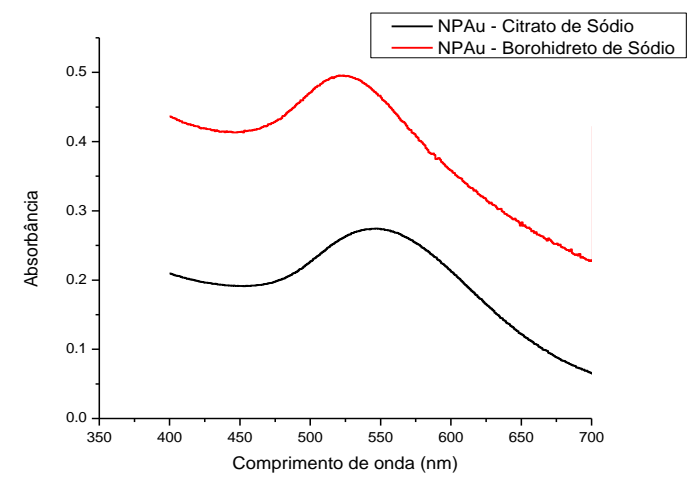

Figura 1 - Espectro de absorção das nanopartículas de ouro sintetizadas com citrato e borohidreto de sódio.

A fim de caracterizar o diâmetro, a morfologia e a dispersão das nanopartículas de ouro, na figura 3 são apresentadas as imagens obtidas por microscopia eletrônica de transmissão (MET).

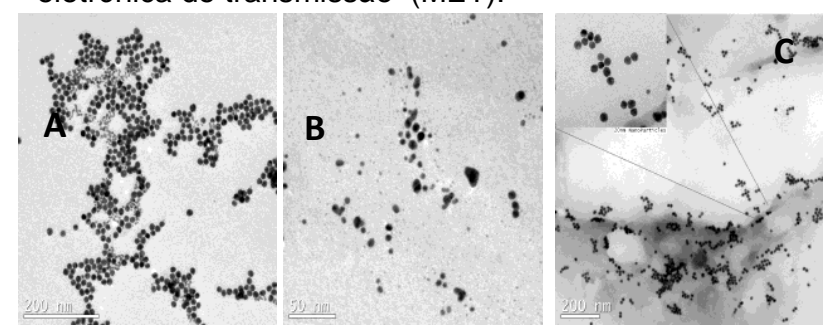

Figura 4 - Detalhes das nanopartículas de ouro: (A) Citrato de sódio Escala de $200 \mathrm{~nm}$ (B) Borohidreto de sódio - Escala 50nm (C) Citrato de Sódio - 200nm.

Na Figura 2 é possível observar as AuNP's em fase de crescimento. Devido à capacidade de estabilização dos íons de citrato as nanoparticulas tendem a apresentar um maior diâmetro que as sintetizadas com borohidreto. Já a amostra sintetizada com borohidreto apresenta grande potencial no processo de formação de núcleos.

$\mathrm{Na}$ figura 3, as imagens de microscopia de força atômica (AFM) e microscopia eletrônica de varredura (MEV) são apresentadas e mostram a dispersão dos nanomateriais, conforme é possível verificar abaixo:

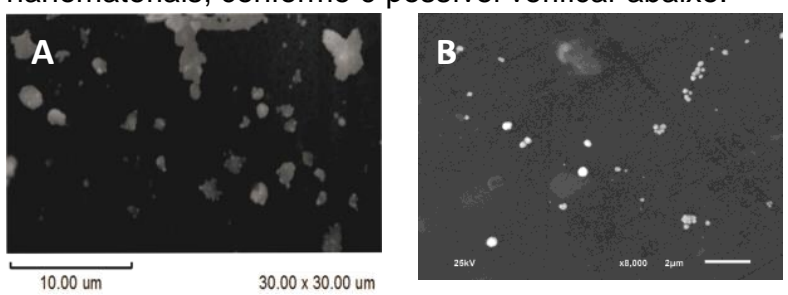

Figura 3 - Nanopartículas de ouro sintetizadas com citrato de sódio, observadas por microscopia de força atômica (A); e microscopia eletrônica de varredura (B).

Na figura 4 abaixo é apresentado as imagens em 3D como resultado da tomografia eletrônica, nota-se nanopartículas predominantemente esféricas e com boa resolução na escala nanométrica

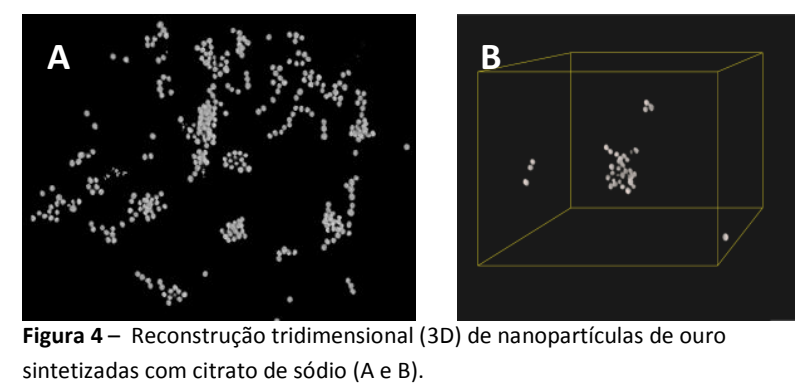

\section{Conclusões}

Foi possível avaliar as diferenças das nanopartículas de ouro sintetizadas por citrato e borohidreto de sódio pelas ferramentas utilizadas. As imagens de MET demonstraram a forma e o tamanho das nanopartículas e o MEV e o AFM mostraram a dispersão dos nanomateriais. A reconstrução $3 \mathrm{D}$ das imagens por tomografia de elétrons possibilitou o estudo da forma exata das nanopartículas, nesse caso, predominantemente esféricas.

\section{Agradecimentos}

Ministério da Ciência e Tecnologia (MCTI / FINEP / CTINFRA PROINFRA 01/2006). Fundação de Amparo à Pesquisa do Espírito Santo (FAPES, 018/2012).

\section{Referências}

[1] K. Page, Th. Proffen, H. Terrones, M. Terrones, L. Lee, Y. Yang, S. Stemmer, R. Seshadri, and A. K. Cheetham, Chem. Phys. Lett. 393 (2004) 385-388.

[2]P. Baptista, E. Pereira, P. Eaton, G. Doria, A. Miranda, I. Gomes, P. Quaresma, R. Franco. Anal Bioanal Chem (2008) 391:943-950

[3] M. A. Melo Jr., S. S. Santos, M. C. Gonçalves, A. F. Nogueira. Quim. Nova, Vol. 35, No. 9, 1872-1878, 2012 